ORIGINAL ARTICLE

\title{
Primary osteoarthritis of hip, knee, and hand in relation to occupational exposure
}

\author{
M Rossignol, A Leclerc, F A Allaert, S Rozenberg, J P Valat, B Avouac, P Coste, E Litvak, P Hilliquin
}

Occup Environ Med 2005;62:772-777. doi: 10.1136/oem.2005.020057

See end of article for authors' affiliations

.....................

Correspondence to:

Dr M Rossignol, Montrea

Department of Public

Health, 1301 Sherbrooke

Street East, Montreal,

Quebec, Canada H2L

1M3; mrossign@

santepub-mtl.qc.ca

Accepted 26 May 2005

\begin{abstract}
Aim: To identify occupations with excess prevalence of osteoarthritis of the knee, hip, and hand in a nationwide survey and to compare occupations with and without excess prevalence with regard to biomechanical stresses and severity of osteoarthritis.

Methods: Patients presenting with osteoarthritis of the knee, hip, or hand were recruited throughout France by their treating physician who collected information on history, including age at onset, occupation, and occupational stresses to joints. Severity was assessed using joint specific functional status questionnaires: Lequesne for the hip and knee and Dreiser for the hand. The distribution of osteoarthritis patients by occupation was compared with the distribution of occupations in all workers in France to obtain prevalence rate ratios.

Results: Occupations with the greatest prevalence rate ratio were female cleaners $(6.2 ; 95 \% \mathrm{Cl} 4.6$ to 8.0$)$, women in the clothing industry (5.0; $95 \% \mathrm{Cl} 3.9$ to 6.3 ), male masons and other construction workers (2.9; $95 \% \mathrm{Cl} 2.6$ to 3.3$)$, and agriculture male and female workers $(2.8 ; 95 \% \mathrm{Cl} 2.5$ to 3.2$)$. A twofold greater prevalence rate was observed within certain occupations between self-employed and salaried workers. Early onset of osteoarthritis was seen in the more heavy labour jobs with almost $40 \%$ of patients reporting their first symptoms before the age of 50 .

Conclusion: The early onset and severity of osteoarthritis in certain occupations warrants an urgent need for occupation specific studies for the development and evaluation of preventive strategies in this leading cause of disability in Western countries.
\end{abstract}

$\mathrm{T}$ wo systematic reviews have looked at the relation between occupation and osteoarthritis of the hip and knee and have concluded that the strength of the scientific evidence supporting this relation is moderate. ${ }^{12}$ No such review exists for osteoarthritis of the hand. Specific occupations have been identified for the risk of developing osteoarthritis, but the description of occupational hazards leading to osteoarthritis remains too vague to propose specific preventive measures. ${ }^{3}$ The present study is the second nationwide survey of patients consulting for osteoarthritis of the knee, hip, or hand in France. ${ }^{4}$ The specific objectives were to identify occupations with excess prevalence of osteoarthritis, and to describe these occupations with regard to severity of osteoarthritis and exposure to biomechanical stresses.

\section{METHODS}

This study was a nationwide cross sectional survey of osteoarthritis patients conducted in France between January and September 2003. From an established network of primary care all across France, 1394 physicians agreed to participate in each recruiting their first two patients consulting for osteoarthritis of the hip, knee, or hand-regardless of the current or past diagnostic method used on that patientand who consented by writing to participate in the study. Patients had to be between the ages of 20 and 80 and had to have occupied a job for one year or more during their lifetime, excluding housewives and Armed Forces personnel. Physicians filled out a questionnaire containing information on age, sex, height, and weight of the patients, and their past medical history including age of first onset of osteoarthritis symptoms and trauma to the joints. In addition, assessment of functional limitations due to osteoarthritis at the time of the survey was obtained using the Lequesne questionnaire, standardised and validated for osteoarthritis of the hip and knee, and the Dreiser questionnaire for osteoarthritis of the hand. $^{5-8}$

Patients reported the occupation that they held the longest during their lifetime whether or not they were occupationally active at the time of the survey. This definition corresponded to the one used in the National Survey on Health Impairment and Disability of 1998 in France and the same coding scheme was used to group occupations in 30 categories. ${ }^{9}{ }^{10}$ Coding of occupations in France is not only based on the type of occupation and sector of activity but also on the professional status-self-employed or salaried. This is why some occupational groups such as construction workers are found in two distinct categories, one as self-employed and one as salaried workers. These categories were kept distinct in the analyses. Occupational exposure to biomechanical stresses was reported to the treating physician by yes or no, on five items adapted from a population survey questionnaire: "During your entire professional life, did you (the patient) have to regularly 1) lift or carry heavy objects, 2) keep your affected joint in uncomfortable positions, 3) work in a vibrating vehicle or with vibrating tools, 4) repeat the same movements continuously and 5) work at a pace set by a machine?". ${ }^{11}$

The number of patients in each occupational category (observed cases) was divided by the number expected in that category, calculated using the national distribution of occupations described in the French National Survey on Health Impairment and Disability for the year 1998, adjusted for age and sex. ${ }^{10}$ This provided an estimate of the prevalence rate ratio which was interpreted as an excess prevalence of osteoarthritis in a particular occupational grouping if it was superior to 1.0. The assumption underlying this interpretation was that the distribution of patients included in the survey was not biased compared to the

Abbreviations: BMI, body mass index 
distribution of all osteoarthritis patients in France with regard to their occupation. Confidence intervals at $95 \%$ were obtained by using the square root approximation of the $\chi^{2}$ distribution. ${ }^{12}$ Occupational categories that showed a statistically significant excess prevalence of osteoarthritis were compared with all other patients in the survey on their functional score, age at onset, and exposure to the five biomechanical exposure items. Bivariate comparisons used the $\chi^{2}$ test. Multivariate analyses were performed with logistic regressions comparing occupations with and without excess prevalence (dependant variable), after controlling for age, body mass index (BMI), and history of trauma to the joint. As the variable on duration of the job held the longest during the lifetime was highly correlated with age, only the later was used as a control variable. All analyses were performed separately for men and women and for hip, knee, and hand joints where appropriate.

\section{RESULTS}

The 1394 participating physicians came from all 95 departments (administrative districts) in France. They were slightly older than all physicians in France (mean age of $48.0 v 46.7$ ), males were overrepresented with $88.7 \%$ compared with $74.1 \%$ for all French physicians, and urban practices were underrepresented with $57.0 \%$ compared with $66.9 \%$ in all of France. Of the 2842 patients included in the study, 54.9\% were men and the mean age was 61.8 years (standard deviation (SD) 9.3) (table 1). The duration of osteoarthritis symptoms was reported to be on average 7.4 years with no difference between men and women. The median age at start of osteoarthritis was 55 years, the mode 50 years old, and $75 \%$ of the patients reported their osteoarthritis symptoms to have begun before the age of 61. Because the participating physicians enrolled their first two patients who volunteered and did not keep an account of those who did not, we have no indication of the participation rate. In $85.2 \%$ of the patients recruited, the consultation was a follow up visit for osteoarthritis. The physician reported that the diagnosis was confirmed with at least a plain $x$ ray in $90.7 \%$ of the patients included, the other $9.3 \%$ having had an $x$ ray done by another physician or had been diagnosed clinically only. Knee osteoarthritis affected over half $(59.3 \%)$ of the patients. The second position in men was osteoarthritis of the hip with $35.4 \%$ and in women, osteoarthritis of the hand with $42.7 \%$, which also represented the highest rate of bilaterality with $70.9 \%$ of women having a bilateral hand osteoarthritis problem. The rate of bilaterality was also high in men with hand osteoarthritis and in men and women with knee osteoarthritis, all reaching over $40 \%$. Finally, compared with men, women had fourfold more occurrences of two or more types of joint affected simultaneously.

\section{Occupational exposure to biomechanical stresses}

Overall, $41.3 \%$ of the patients were actively employed at the time of the consultation, of which $22.9 \%$ were on temporary sick leave caused by osteoarthritis. The proportion of patients who reported having been exposed regularly during their professional life to the five biomechanical stresses is shown in table 2 by sex and location of osteoarthritis. There was no difference in reported exposure to any of the items between patients who had osteoarthritis of the hip and osteoarthritis of the knee. However, there were differences between osteoarthritis of the lower extremity (hip and knee combined) and of the hand in the reported exposure to three stresses after controlling for age, BMI, and history of trauma. Uncomfortable position of the affected joint was 2.5 times more likely to be reported in men and women who suffered from lower extremity osteoarthritis (odds ratio $(\mathrm{OR})=2.5$; 95\% CI 1.6 to 4.1 ). Men and women exposed to that stress
Table 1 Descriptive statistics of the study population

\begin{tabular}{|c|c|c|c|}
\hline & $\begin{array}{l}\text { All } \\
(n=2834)\end{array}$ & $\begin{array}{l}\text { Men } \\
(n=1615)\end{array}$ & $\begin{array}{l}\text { Women } \\
(n=1219)\end{array}$ \\
\hline Mean age (SD) & $61.8(9.3)$ & $61.1(9.3)$ & $62.5(9.3)$ \\
\hline $\begin{array}{l}\text { Mean age at start } \\
\text { of symptoms (SD) } \\
\text { Joint affected }(\%)^{*}\end{array}$ & $54.4(9.1)$ & $54.2(8.9)$ & 54.7 (9.3) \\
\hline Knee & 59.3 & 63.9 & 53.3 \\
\hline Hip & 31.8 & 35.4 & 27.0 \\
\hline Hand & 27.4 & 15.8 & 42.7 \\
\hline$\geqslant 2$ of above & 8.8 & 5.5 & 20.6 \\
\hline Missing & 13.9 & 13.5 & 14.9 \\
\hline \multicolumn{4}{|l|}{ Bilateral OA (\%) } \\
\hline Knee & 43.1 & 41.1 & 46.8 \\
\hline Hip & 26.6 & 24.3 & 31.2 \\
\hline Hand & 65.6 & 55.1 & 70.9 \\
\hline \multicolumn{4}{|l|}{ Professional status } \\
\hline Active & 41.3 & 45.5 & 36.2 \\
\hline Retired & 54.4 & 52.6 & 56.8 \\
\hline Unemployed & 4.3 & 1.9 & 7.0 \\
\hline $\begin{array}{l}\text { History of trauma } \\
\text { in joint affected by }\end{array}$ & 24.0 & 28.0 & 18.7 \\
\hline $\mathrm{BMl} \dagger \geqslant 25$ & 60.7 & 70.6 & 48.7 \\
\hline
\end{tabular}

also reported a disability score on the Lequesne functional scale equal or greater to 12.5 (extreme disability) in $25 \%$ of patients compared with $20 \%$ in those unexposed $(\mathrm{p}<0.001)$. The two other stresses-repetition of movements and working at machine pace-were associated with hand osteoarthritis. Women with hand osteoarthritis reported one of the two exposures 3.6 times more often than patients with hip or knee osteoarthritis (OR $=3.6 ; 95 \%$ CI 2.4 to 5.7$)$. In men the association was weaker and not statistically significant $(\mathrm{OR}=1.5 ; 95 \%$ CI 0.9 to 2.5$)$. The median scores of severity in the two functional limitation scales were comparable between men and women and corresponded to clinically severe osteoarthritis except for hand osteoarthritis in men which corresponded to moderate severity. Among the cofactors, a history of trauma to the affected joint and a BMI superior or equal to 25 were both statistically more prevalent in knee osteoarthritis than the two other joints in women (table 2). In men, these differences were weaker.

Prevalence rate ratios of osteoarthritis by occupation Table 3 shows the number of observed male and female patients in each of the 30 occupational categories and the ratio with their corresponding expected number calculated from the French National Survey distribution of the workforce in France. The top 10 categories showed, in decreasing order, a statistically significant prevalence rate ratio of osteoarthritis in men, women, or both. In first position, female cleaners had a prevalence rate of osteoarthritis over six times higher than expected (category 68: prevalence rate ratio $=6.2 ; 95 \%$ CI 4.6 to 8.0 ). Their distribution of osteoarthritis by site was similar to the entire female patient population but they reported being more disabled particularly from hip osteoarthritis than all other occupations, with $26.9 \%$ having a Lequesne score superior to 10 (severe) against $14.3 \%$ for the whole female study population $(p=0.05)$. In terms of exposure to the five biomechanical stresses, they reported more frequently having to keep uncomfortable positions than all other occupations $(87 \% v 60 \%, \mathrm{p}<0.001)$.

In the second and third occupational categories, distinguished only by the professional status of workers (selfemployed in category 21 and salaried in 63), women in the clothing sector $(56.7 \%$ of the two categories combined) with a few bakers and hairdressers, showed an excess prevalence 
Table 2 Perceived biomechanical stresses by sex and osteoarthritis location

\begin{tabular}{|c|c|c|c|c|c|c|}
\hline & \multicolumn{3}{|l|}{ Men } & \multicolumn{3}{|l|}{ Women } \\
\hline & Knee ( $n=862)$ & Hip ( $n=478)$ & Hand $(n=213)$ & Knee $(n=537)$ & Hip (n= 272) & Hand $(n=430)$ \\
\hline \multicolumn{7}{|l|}{ Biomechanical stresses (\%) } \\
\hline Lift or carry heavy objects & 74.5 & 71.8 & 71.4 & 50.1 & 50.4 & 44.2 \\
\hline $\begin{array}{l}\text { Uncomfortable position of the } \\
\text { joint with osteoarthritis }\end{array}$ & 76.8 & 71.3 & $65.3^{*}$ & 65.4 & 65.1 & $55.1^{*}$ \\
\hline $\begin{array}{l}\text { Work in vibrating vehicle or with } \\
\text { vibrating tools }\end{array}$ & 35.5 & 38.5 & 39.4 & 5.4 & 3.7 & 4.9 \\
\hline Repeat same movements continuously & 56.1 & 51.5 & 61.0 & 55.7 & 55.9 & $72.6^{*}$ \\
\hline Work at a pace set by a machine & 18.6 & 18.4 & $22.1^{*}$ & 10.1 & 7.0 & $17.9^{*}$ \\
\hline \multicolumn{7}{|l|}{ Cofactors } \\
\hline Mean age (years) & 61.2 & $62.4 \dagger$ & $60.6^{*}$ & 63.5 & 63.8 & $61.7^{*}$ \\
\hline Mean age at start of symptoms (years) & 53.9 & 55.3 & 52.9 & 55.2 & 54.9 & 53.1 \\
\hline Functional score (median)§ & 10.0 & 10.0 & 7.0 & 11.0 & 11.0 & 10.0 \\
\hline $\begin{array}{l}\text { History of trauma in joint affected by } \\
\text { osteoarthritis (\%) }\end{array}$ & 33.8 & $18.2 \dagger$ & 28.9 & 25.0 & $14.8+$ & $18.0^{*}$ \\
\hline $\mathrm{BMI} \neq \geqslant 25$ & 73.0 & 72.8 & $60.1^{*}$ & 54.9 & $49.6+$ & $37.2^{*}$ \\
\hline \multicolumn{7}{|c|}{$\begin{array}{l}\text { *Difference (knee }+ \text { hip) versus hand (dependant variable) excluding subjects with joint involvement in more than one category, statistically significant at } \mathrm{p}<0.05 \text { in } \\
\text { multiple logistic regressions including all cofactors in the table. } \\
\text { †Difference in knee versus hip (dependant variable) excluding subjects with joint involvement in more than one category, statistically significant at } \mathrm{p}<0.05 \text { in } \\
\text { multiple logistic regressions including all cofactors in the table. } \\
\text { †Body mass index = weight in kilograms / (height in metres) } \\
\text { §Lequesne functional score (from } 0 \text {, no incapacity to } 24, \text { maximum incapacity) for knee and hip osteoarthritis, Dreiser functional score (from } 0 \text {, no incapacity to } 30 \\
\text { maximum incapacity) for hand osteoarthritis. }\end{array}$} \\
\hline
\end{tabular}

ranging between 3.2 for salaried workers (95\% CI 2.5 to 4.1 ) and 5.0 for self-employed workers (95\% CI 3.9 to 6.3). These two groups were remarkable in that they had the highest proportion of osteoarthritis to the hands $(48.0 \%)$ in the whole study population $(36.2 \%)$ ( $\mathrm{p}=0.01)$. They also reported a greater disability from their hand osteoarthritis with $42.8 \%$ who reported a score of $\geqslant 12$ on the Dreiser scale, which represents extreme disability compared to $25.0 \%$ in all other

Table 3 Prevalence rate ratio of observed $(O)$ to expected $(E)$ number of cases of osteoarthritis by occupational category and sex

\begin{tabular}{|c|c|c|c|c|c|c|}
\hline \multirow[b]{2}{*}{ Occupation (code number in French classification) } & \multicolumn{3}{|c|}{ Men* } & \multicolumn{3}{|c|}{ Women* } \\
\hline & 0 & O/E & $95 \% \mathrm{Cl}$ & 0 & O/E & $95 \% \mathrm{Cl}$ \\
\hline Cleaners: commercial and industrial (68) & 3 & 0.1 & 0.0 to 0.1 & 52 & 6.2 & 4.6 to 8.0 \\
\hline $\begin{array}{l}\text { Self-employed in construction, mechanics, clothing, } \\
\text { and food sectors (21) }\end{array}$ & 280 & 2.9 & 2.6 to 3.3 & 67 & 5.0 & 3.9 to 6.3 \\
\hline $\begin{array}{l}\text { Salaried workers in construction, mechanics, } \\
\text { clothing, and food sectors (63) }\end{array}$ & 245 & 1.9 & 1.7 to 2.2 & 60 & 3.2 & 2.5 to 4.1 \\
\hline Agriculture (10) & 250 & 2.8 & 2.5 to 3.2 & 126 & 2.7 & 2.3 to 3.2 \\
\hline Teachers, physical educators, professional sportsmen (42) & 29 & 2.5 & 1.7 to 3.5 & 46 & 0.9 & 0.7 to 1.2 \\
\hline Retail commerce and small service businesses (22) & 50 & 0.7 & 0.5 to 0.9 & 80 & 1.9 & 1.5 to 2.3 \\
\hline Public services engineers (33) & 21 & 1.8 & 1.1 to 2.6 & 2 & 0.1 & 0.01 to 0.3 \\
\hline Public services assistants (teaching and health) (52) & 77 & 1.5 & 1.2 to 1.8 & 228 & 1.6 & 1.4 to 1.8 \\
\hline Liberal professions (health and others) (31) & 36 & 1.6 & 1.1 to 2.2 & 13 & 1.2 & 0.6 to 2.0 \\
\hline Blue collar workers unspecified (101)† & 167 & 1.3 & 1.1 to 1.5 & 133 & 1.3 & 1.1 to 1.6 \\
\hline Clergy, ministers of religion (44) & 1 & 1.3 & 0.0 to 5.1 & - & - & - \\
\hline Arts, show business, information technology (35) & 8 & 1.1 & 0.5 to 2.1 & 7 & 2.0 & 0.8 to 3.7 \\
\hline Truck, bus, and taxi drivers (64) & 69 & 1.0 & 0.8 to 1.2 & 3 & 0.7 & 0.1 to 1.6 \\
\hline Material handling machine operators (65) & 49 & 0.8 & 0.6 to 1.0 & 2 & 0.5 & 0.1 to 1.6 \\
\hline Occupations in health and social services (43) & 21 & 0.7 & 0.5 to 1.1 & 52 & 0.5 & 0.4 to 0.7 \\
\hline Occupations in retail and wholesales (55) & 22 & 0.7 & 0.4 to 1.0 & 67 & 0.9 & 0.7 to 1.1 \\
\hline Salaried workers in agriculture $(69)^{*}$ & 16 & 0.6 & 0.4 to 0.9 & 5 & 1.0 & 0.3 to 2.0 \\
\hline Administrative and clerical staff (54) & 25 & 0.5 & 0.3 to 0.7 & 122 & 0.7 & 0.6 to 0.8 \\
\hline Material handlers (67) & 36 & 0.5 & 0.3 to 0.6 & 14 & 0.2 & 0.1 to 0.2 \\
\hline Police, penitentiary, and firefighting (53) & 32 & 0.5 & 0.3 to 0.6 & 6 & 1.0 & 0.4 to 2.0 \\
\hline Middle management occupations (46) & 39 & 0.5 & 0.3 to 0.6 & 23 & 0.3 & 0.2 to 0.5 \\
\hline Mining, machine operators, metal and welding (62) & 64 & 0.4 & 0.3 to 0.5 & 6 & 0.1 & 0.1 to 0.3 \\
\hline University professors and researchers (34) & 19 & 0.4 & 0.2 to 0.6 & 22 & 0.7 & 0.4 to 1.0 \\
\hline Industrial, laboratory, and information technicians (47) & 28 & 0.3 & 0.2 to 0.5 & 4 & 0.2 & 0.1 to 0.4 \\
\hline Public administration middle management (45) & 4 & 0.3 & 0.1 to 0.7 & 8 & 0.6 & 0.3 to 1.1 \\
\hline Top management in industry and commerce (23) & 8 & 0.3 & 0.1 to 0.5 & 2 & 8.1 & 0.8 to 23.1 \\
\hline Middle management in industry and commerce (37) & 24 & 0.3 & 0.2 to 0.4 & 6 & 0.2 & 0.1 to 0.4 \\
\hline $\begin{array}{l}\text { Technical management in industry, transportation, and } \\
\text { communications (38) }\end{array}$ & 12 & 0.2 & 0.1 to 0.3 & - & - & - \\
\hline Hotel, restaurant, and personal services $(56)$ & 5 & 0.2 & 0.1 to 0.4 & 127 & 0.7 & 0.6 to 0.9 \\
\hline Foreman in industrial and services industry (48) & 14 & 0.2 & 0.1 to 0.3 & 2 & 0.5 & 0.1 to 1.4 \\
\hline
\end{tabular}

Bold figures correspond to statistically significant excess $O A$ compared with what was expected.

${ }^{*}$ All blue collar workers, including categories 67 and 68 .

$\mathrm{O}$, actual number of patients observed in each category; $\mathrm{O} / \mathrm{E}$ : prevalence rate ratio (observed over expected) adjusted for age. Expected numbers obtained from the distribution of the French workforce by occupational categories in the National Survey on Health Impairment and Disability of 1998 in France. 
women with hand osteoarthritis $(\mathrm{p}=0.04)$. They also reported a higher prevalence rate of repeating the same movements with $88 \%$ against $61 \%$ for all occupations together $(\mathrm{p}<0.001)$.

Men in the same two categories, were represented by masons $(37.1 \%$ of categories 21 and 63 ) painters, plumbers, carpenters, and automobile mechanics. As it was the case for women, the excess prevalence was somewhat greater among self-employed (prevalence rate ratio $=2.9,95 \%$ CI 2.6 to 3.3 ) than among salaried workers (prevalence rate ratio $=1.9$, 95\% CI 1.7 to 2.2 ). On the other hand, the latter group showed a more premature development of osteoarthritis than all other occupations with $66.3 \%$ of patients reporting their first symptoms before the age of 55 and $38.3 \%$ before the age of $50(p=0.001)$. This observation was not made in the selfemployed category. Overall, the distribution of osteoarthritis by joint was similar to all men in the survey but they reported doing more lifting of heavy objects and keeping uncomfortable positions $(90 \% \vee 73 \%, \mathrm{p}<0.001$ and $88 \% \vee 74 \%, \mathrm{p}<0.001$ respectively).

The next category (number 10) was farmers and agriculture workers with an excess prevalence of osteoarthritis that was almost three times that of the study population, with almost identical results between men (prevalence rate ratio $=2.8 ; 95 \%$ CI 2.5 to 3.2 ) and women (prevalence rate ratio $=2.7 ; 95 \%$ CI 2.3 to 3.2). Agriculture workers reported a statistically higher prevalence rate of exposure than all other occupations to four of the five biomechanical stresses in men (lifting, uncomfortable postures, vibrations, and machine pace) and three in women (lifting, uncomfortable postures, and vibrations) $(\mathrm{p}<0.001)$. In men, the difference with all occupations was especially high for exposure to vibrations $(74 \% v 37 \%)$ and in women, for lifting of heavy objects $(83 \% v$ $47 \%$ ). The distribution of osteoarthritis by anatomical location was unremarkable compared to the whole study population although the onset of osteoarthritis appeared to be delayed, with $33.2 \%$ who reported symptoms before the age of 55 compared with $49.3 \%$ in the whole study population $(\mathrm{p}<0.001)$.

The other categories with a statistically significant excess prevalence were male teachers, physical educators, and professional sportsmen (category 42), female retail employees (category 22), public services engineers (category 33), teaching and health assistants (category 52), male liberal professions in health (category 31), and blue collar workers unspecified (category 101). The latter category showed a similar $30 \%$ excess prevalence in male and female workers. They were noticeable for their higher prevalence rate of reporting repetition of movements $(76 \% \vee 58 \%, p<0.001)$ and working at a machine set pace $(38 \% v 16 \%, \mathrm{p}<0.001)$. A specific subcategory of blue collar workers, material handlers (category 67), did not show excess prevalence but was remarkable in having the most precocious onset of osteoarthritis of all patients. Men and women in that category declared an onset of symptoms before the age of 55 years in proportions, respectively, of $76.5 \%(p=0.001)$ and $71.4 \%(p=0.02)$ compared with $49.7 \%$ for the whole study population. They also reported a statistically higher prevalence rate of lifting of heavy objects both in male $(91 \% \vee 73 \%, \mathrm{p}=0.01)$ and female $(79 \% \vee 47 \%, \mathrm{p}=0.02)$ workers.

Of the other occupations that reported a higher prevalence rate of exposure to biomechanical stresses than the whole study population, but without showing an excess prevalence of osteoarthritis, were male drivers (category 64) who declared the highest exposure to vibrations compared with the rest of the population $(74 \% \vee 37 \%, \mathrm{p}<0.001)$, and female employees in hotel, restaurant, and personal services (category 56) who reported a combination of high prevalence rate of lifting of heavy objects $(68 \% v 47 \%, \mathrm{p}<0.001)$ and of uncomfortable positions ( $75 \%$ v 60\%, $\mathrm{p}<0.001)$.

When all occupational categories with a statistically significant excess prevalence of OA were grouped together and compared with the other occupations, exposure to biomechanical stresses was significantly higher for osteoarthritis of the knee and hip but not for osteoarthritis of the hand. After controlling for age, sex, BMI, history of trauma, and severity of osteoarthritis, male subjects who were in an excess prevalence group were 12.8 times more likely $(\mathrm{OR}=12.8 ; 95 \%$ CI 6.0 to 27.4$)$ to report both regularly lifting heavy objects and having to keep the affected joint in uncomfortable positions. In women that probability was 26.4 times higher ( $\mathrm{OR}=26.4 ; 95 \%$ CI 7.8 to 88.9 ).

\section{DISCUSSION}

The quality of the information on occupation and occupational exposures collected in this cross sectional survey depended on the accuracy of recall which is likely to be different between patients who were actively employed and those retired. This however should not represent a major source of bias in the comparison between occupations. In that respect it was interesting to observe significant differences in occupational exposures between osteoarthritis of the hand and of the lower extremity which indicated a certain element of validity to the information. Another problem related to the cross sectional nature of the survey was the telescoping of historic information with the current functional status of patients with osteoarthritis. The functional status however was not used here as an outcome but only as a descriptor, along with the duration of symptoms, of osteoarthritis patterns in occupations that were found with excess prevalence.

The distribution of osteoarthritis by sex in our study did not completely conform to what has been observed in the general population; namely, we did not observe a higher prevalence of knee osteoarthritis in women compared with men. ${ }^{13}$ This might be explained in part by the exclusion of housewives from our survey. This is not to say that housework is not a risk for osteoarthritis but we could not fit this category into the classification of occupations that we used in the estimation of expected number of cases. The use of the 1998 National Survey on Health, Impairment and Disability to compare the occupational distribution of the French workforce with that of patients recruited in 2003 could have induced a distortion, especially for older workers who had retired. This might be particularly true for manual occupations that have decreased in frequency over the last quarter of century. This could lead to an underestimation of expected cases and an overestimation of the prevalence ratio. This problem however should not bias the comparison of manual occupations between themselves.

\section{Occupations at risk}

Recruitment of patients within this network of participating physicians should not bias the results as it was found that their distribution was very similar to that of all physicians across France. A bias however could arise from differential referral patterns between occupations. If such bias existed, it would underestimate the prevalence ratios in occupational groups with low referral rates. This is why no direct comparison was made between occupational groups. The cross sectional nature of this survey did not allow the observation of risks in different occupations as we only compared observed and expected prevalent cases from the national distribution of occupations. Given that there is no cure for osteoarthritis, excess prevalence in occupations may be the result of a higher incidence, an onset at a younger age, or a combination of both. Controlling for both age and age at 
beginning of symptoms in multivariate analyses contributed to highlight the incidence component. We did not have precise information on duration of specific exposures. However, the correlation between age of onset and prevalence ratio of osteoarthritis provided information on the potential intensity of these exposures.

Female cleaners showed a unique pattern of osteoarthritis with excess to all three joints but greater suffering from the lower limb. In order to correctly identify this occupational group, we had to sort out, within the French classification, cleaners in office buildings from those in hotels, and cleaners working for an enterprise from those working in personal services. There is certainly some degree of misclassification in our survey that could lead to an overestimation of the excess prevalence. However, the greater disability expressed in this group indicated that the results cannot only be explained by coding errors. Previous studies looking at housekeeping tasks and osteoarthritis with mixed results have not identified risk factors. ${ }^{4-16}$ The observation of occupational exposure to uncomfortable positions reported in this group was not sufficient to identify these factors. Priority should be given to investigating this group of workers with the goal of developing prevention strategies.

Women in the clothing industry combined a high prevalence rate ratio and large number of observed cases. The risk pointed toward disabling osteoarthritis of the hand in relation to exposure to repetitive movements. The exact nature of hand osteoarthritis was not investigated in this population study. Hand osteoarthritis and occupation, including textile workers, has been investigated with mixed results. ${ }^{17}$ 17-21 Specific biomechanical stresses have been suggested for the study of hand symptoms in textile workers. $^{22}$ The greater prevalence rate in self-employed compared with salaried workers in our study indicated that working conditions, including regulation of working hours and other organisational factors, may also play an important role in the development of hand osteoarthritis. Studies comparing salaried and self-employed workers in this sector would help identify these factors.

Masons and other construction workers topped the risk of osteoarthritis among male workers with high excess prevalence and a large number of workers affected. Construction workers have been identified as being at risk for osteoarthritis of various joints with results compatible to ours. ${ }^{14} 1618$ 23-25 We found that the prevalence rate was higher among the self-employed; however, salaried workers showed a more premature onset of osteoarthritis. These findings can probably be partly explained by misclassification of patients in the two categories. They remain puzzling however and could indicate that different occupational risks can act independently on the frequency and severity of osteoarthritis. Precocious osteoarthritis was also observed among material handlers. The prematurity of the onset of occupational osteoarthritis has not yet been studied. It seems that the premature wearing out of the joints is not only associated with heavy labour but also with some of the characteristics that differentiate the salaried from the self-employed workers-perhaps showing that less variety in tasks leads to a greater concentration of joint stresses. This finding deserves clinical and radiological screening studies to identify factors associated with early symptomatic osteoarthritis.

The agriculture sector has been historically one of the first to be identified in relation to osteoarthritis of the hip and more recently of the knee. ${ }^{26}$ In a recent study, animal and dairy productions and working in a small size farm were particularly associated with the risk of hip osteoarthritis. ${ }^{27}$ In our observations, all three joints were affected. As other authors have hypothesised, the combination of intense exposure to heavy labour of varied nature and repeated local stresses, especially at a young age, could favour a systemic mechanism to the development of osteoarthritis. ${ }^{13}$ This argument would support the implementation of preventive measures as a priority to reduce the intensity of physical labour in this sector-particularly for young male and female farm workers.

Osteoarthritis is not a condition that has a uniform aetiology and pathology. Our questionnaire was able to identify different occupational exposure patterns such as repetitive movements in osteoarthritis of the hand in clothing industry workers and heavy labour for osteoarthritis of the lower limb. Although they are not clear enough to lead to specific preventative recommendations, these patterns contribute to further define groups at risk and guide future research. Particularly, the early onset of osteoarthritis found in construction and material handling occupations would justify the undertaking of prospective cohort studies to look at this issue carefully.

\section{ACKNOWLEDGEMENTS}

This study was made possible in part by the contribution of the Expanscience Laboratories, Courbevoie, France. The authors wish to thank Jean-François Chastang and Nadine Kaniewski from INSERM U88, St-Maurice, France, for their assistance in coding and computing, Markku Heliövaara for his precious advice, and Bernard Savarieau and Chantal Rousseau for coordinating this project. They are also grateful to the INSEE department "surveys and demographic studies" and to Pierre Mormiche who was responsible for the task force of the National Survey on Health Impairment and Disability in France for their guidance and advice, and to Renaud Urbinelli at Cenbiotech Biostatistical Services, Dijon University Hospital, Dijon, France.

\section{Authors' affiliations}

M Rossignol, Department of Epidemiology, Biostatistics and Occupational Health, McGill University, Montreal, Canada

A Leclerc, INSERM, U88, St-Maurice, France

F A Allaert, Medical Information, CHU Dijon, France

S Rozenberg, Rheumatology, Pitie-Salpetriere Hospital, Paris, France

J P Valat, Faculty of Medicine, Tours University, France

B Avouac, Rheumatology, Henri Mondor Hospital, Créteil, France

P Coste, Expanscience Laboratories, Courbevoie, France

E Litvak, Département de médecine sociale et préventive, Université de Montréal, Montreal, Canada

P Hilliquin, Gilles de Corbeil Hospital, Corbeil, France

Competing interests: Michel Rossignol has received research funds from the sponsor Expanscience Laboratories on behalf of the Department of Epidemiology, Biostatistics and Occupational Health, to conduct part of the analysis and manuscript preparation for this project. Philippe Coste is an employee of the sponsor Expanscience as Medical Director.

\section{REFERENCES}

1 Lievense A, Bierma-Zeinstra S, Verhagen A, et al. Influence of work on the development of osteoarthritis of the hip: a systematic review. J Rheumatol 2001;28:2520-8

2 Maetzel A, Makela M, Hawker G, et al. Osteoarthritis of the hip and knee and mechanical occupational exposure-a systematic overview of the evidence. J Rheumatol 1997;24:1599-607.

3 Rossignol M. Primary osteoarthritis and occupation in the Quebec national health and social survey. Occ Environ Med 2004;61:729-35.

4 Rossignol M, Leclerc A, Hilliquin P, et al. Primary osteoarthritis and occupations: a national cross sectional survey of 10412 symptomatic patients. Occup Environ Med 2003;60:882-6.

5 Lequesne M, Samson M, Gerard P, et al. [Pain-function indices for the followup of osteoarthritis of the hip and the knee]. Rev Rhum Mal Osteoartic 1990;57:32S-36S (in French).

6 Faucher M, Poiraudeau S, Lefevre-Colau MM, et al. Algo-functional assessment of knee osteoarthritis: comparison of the test-retest reliability and construct validity of the WOMAC and Lequesne indexes. Osteoarthritis Cartilage 2002;10:602-10.

7 Dreiser RL, Maheu E, Guillou GB. Sensitivity to change of the functional index for hand osteoarthritis. Osteoarthritis Cartilage 2000;8(Suppl A):S25-8.

8 Dreiser RL, Maheu E, Guillou GB, et al. Validation of an algofunctional index for osteoarthritis of the hand. Rev Rhum Engl Ed 1995;62(Suppl 1):43S-53S.

9 Mormiche P. National survey on health impairment and disability. Courrier des statistiques, INSEE 1998;87:7-18 [in French]. 
10 INSEE. INSEE social classification of occupations. Paris, France: INSEE, 1983 (in French).

11 Heliovaara M, Makela M, Impivaara $O$, et al. Association of overweight, trauma and workload with coxarthrosis. A health survey of 7,217 persons. Acta Orthop Scand 1993:64:513-8.

12 Bernard PM, Lapointe C. Statistical measures in epidemiology. Québec, Canada: Presses de I'Université du Québec 1987, 287-8 [in French].

13 Felson DT, Lawrence RC, Dieppe PA, et al. Osteoarthritis: new insights. Part 1: the disease and its risk factors. Ann Intern Med 2000;133:635-46.

14 Vingard E, Alfredsson L, Goldie I, et al. Occupation and osteoarthrosis of the hip and knee: a register-based cohort study. Int J Epidemiol 1991;20:1025-31.

15 Caspi D, Flusser G, Farber I, et al. Clinical, radiologic, demographic, and occupational aspects of hand osteoarthritis in the elderly. Semin Arthritis Rheum 2001;30:321-31.

16 Holmberg S, Thelin A, Thelin N. Is there an increased risk of knee osteoarthritis among farmers? A population-based case-control study. Int Arch Occup Environ Health 2004:77:345-50.

17 Lawrence JS. Rheumatism in cotton operatives. Br J Ind Med 1961;18:270-6.

18 Dillon C, Petersen M, Tanaka S. Self-reported hand and wrist arthritis and occupation: data from the U.S. National Health Interview SurveyOccupational Health Supplement. Am J Ind Med 2002;42:318-27.
19 Jones G, Cooley HM, Stankovich JM. A cross sectional study of the association between sex, smoking, and other lifestyle factors and osteoarthritis of the hand. J Rheumatol 2002;29:1719-24.

20 Haara MM, Manninen $\mathrm{P}$, Kroger $\mathrm{H}$, et al. Osteoarthritis of finger joints in Finns aged 30 or over: prevalence, determinants, and association with mortality. Ann Rheum Dis 2003;62:151-8.

21 Crijetic S, Kurtagic N, Ozegovic DD. Osteoarthritis of the hands in the rural population: a follow-up study. Eur J Epidemiol 2004;19:687-91.

22 Hadler NM, Gillings DB, Imbus HR, et al. Hand structure and function in an industrial setting. Arthritis Rheum 1978;21:210-20.

23 Stenlund B, Goldie I, Hagberg M, et al. Radiographic osteoarthrosis in the acromioclavicular joint resulting from manual work or exposure to vibration. $\mathrm{Br} J$ Ind Med 1992;49:588-93.

24 O'Reilly SC, Muir KR, Doherty M. Occupation and knee pain: a community study. Osteoarthritis Cartilage 2000;8:78-81.

25 Sandmark H, Hogstedt C, Vingard E. Primary osteoarthrosis of the knee in men and women as a result of lifelong physical load from work. Scand J Work Environ Health 2000;26:20-5.

26 Walker-Bone K, Palmer KT. Musculoskeletal disorders in farmers and farm workers. Occup Med (Lond) 2002;52:441-50.

27 Thelin A, Vingard E, Holmberg S. Osteoarthritis of the hip joint and farm work. Am J Ind Med 2004:45:202-9.

\section{bmjupdates+}

bmjupdates+ is a unique and free alerting service, designed to keep you up to date with the medical literature that is truly important to your practice.

bmjupdates+ will alert you to important new research and will provide you with the best new evidence concerning important advances in health care, tailored to your medical interests and time demands.

Where does the information come from?

bmjupdates+ applies an expert critical appraisal filter to over 100 top medical journals A panel of over 2000 physicians find the few 'must read' studies for each area of clinical interest

Sign up to receive your tailored email alerts, searching access and more...

www.bmjupdates.com 